\title{
SEMICONDUCTOR ELECTROCHEMISTRY OF COAL PYRITE
}

\author{
Technical Progress Report
}

October - December 1992

\author{
by
}

K. Osseo-Asare and Dawei Wei

Department of Materials Science and Engineering

The Pennsylvania State University

University Park, PA 16802

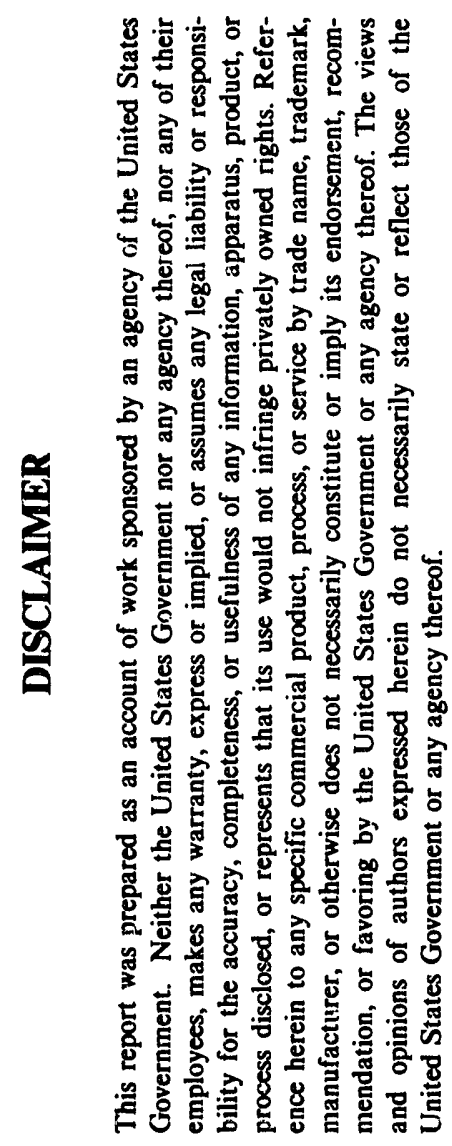

\author{
Prepared for the \\ United States Department of Energy \\ Under \\ Grant No. DE-FG22-91 PC 91303
}

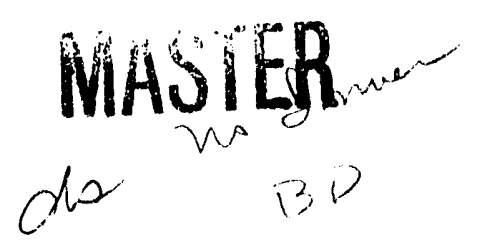

WTHATIOM THIS JOCUMENT IS UNLIMITEO 


\title{
SEMICONDUCTOR ELECTROCHEMISTRY OF COAL PYRITE
}

\author{
Technical Progress Report \\ October - December 1992
}

\author{
by \\ K. Osseo-Asare and Dawei Wei \\ Department of Materials Science and Engineering \\ The Pennsylvania State University \\ University Park, PA 16802
}

February 1993 


\section{TABLE OF CONTENTS}

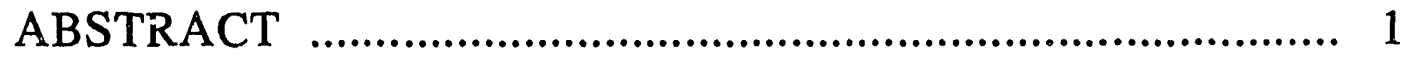

PROJECT OBJECTIVES …............................................... 1

STATEMENT OF WORK ................................................. 2

DESCRIPTION OF TECHNICAL PROGRESS :

INTRODUCTION ................................................... 2

EXPERIMENTAL ................................................. 4

RESULTS AND DISCUSSION ..................................... 5

CONCLUSIONS _....................................................... 7

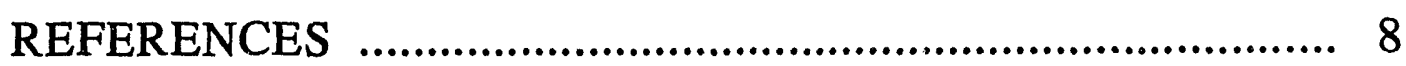




\begin{abstract}
The kinetic study of the reaction between sulfide and ferrous ions in solution suggested that the black species formed initially is FeHS ${ }^{+}$ intermediate. To further confirm this mechanism, the experiments aimed at establishing the stoichiometry for the intermediate were carried out thermodynamically with a stopped-flow spectrophotometric technique. The results showed that the mole ratio of $\mathrm{HS}-/ \mathrm{Fe}^{2+}$ is 1 to 1 for the intermediate product, which is in good agreement with the kinetic results previously obtained. Furthermore, the equilibrium constant for the reaction $\mathrm{Fe}^{2+}+$ $\mathrm{HS}^{-}=\mathrm{FeHS}^{+}$was determined as $\mathrm{K}=10^{4.34}$. The forward rate constant is $10^{3.81}(\mathrm{~mol} / \mathrm{l})^{-1} \mathrm{sec}^{-1}$ and the backward rate constant is $10^{-0.53}(\mathrm{~mol} / \mathrm{l})^{-1} \mathrm{sec}^{-1}$.
\end{abstract}

\title{
PROJECT OBJECTIVES
}

This project seeks to advance the fundamental understanding of the physico-chemical processes occurring at the pyrite/aqueous interface, in the context of coal cleaning, coal desulfurization, and acid mine drainage. A novel approach to the study of pyrite aqueous electrochemistry is proposed, based on the use of both synthetic and natural (i.e. coal-derived) pyrite specimens, the utilization of pyrite both in the form of micro (i.e. colloidal and subcolloidal) and macro (i.e. rotating ring disk) electrodes, and the application of in-situ direct electroanalytical and spectroelectrochemical 
characterization techniques. Central to this research is the recognition that pyrite is a semiconductor material. (Photo) electrochemical experiments will be conducted to unravel the mechanisms of anodic and cathodic processes such as those associated with pyrite decomposition and the reduction of oxidants such as molecular oxygen and the ferric ion.

\section{STATEMENT OF WORK}

The experiments to be conducted fall into two main groups, depending on whether the pyrite specimens are used in the form of (a) nanoparticle microelectrodes, or (b) planar surface macroelectrodes. In the first case, synthetic pyrite microelectrodes will be used in the form of nanoparticles and the in-situ observation of the evolution of particle size and reaction products will be accomplished via photon correlation, absorption, and fluorescence spectroscopy techniques. In the second case, the experimental system will be based on a rotating ring disk electrode (RRDE) assembly, with coal pyrite serving as the disk and a $\mathrm{Pt}$ (or $\mathrm{Ag}, \mathrm{Cu}$ ) ring electrode permitting direct in-situ electroanalytical determination of reaction products.

\section{DESCRIPTION OF TECHNICAL PROGRESS:}

\section{INTRODUCTION}

The study of FeS formation in aqueous solution is very useful for understanding the mechanisms of pyrite formation. FeS can be formed by the reaction between aqueous sulfide and dissolved Fe(II) salts. A black precipitate is observed immediately when the two solutions are mixed. It 
has been suggested in a number of studies (See review by Morse et al., 1987; Schoonen and Barnes, 1991a,1991b, 1991c) that the black material is iron sulfide which is X-ray amorphous, with the chemical composition varying from $\mathrm{Fe}_{0.87} \mathrm{~S}$ to $\mathrm{FeS}_{1.1}$ (Berner, 1962, 1964, 1967; Rickard, 1969, 1975; Sweeney and Kaplan, 1973).

However, some arguments still exist. What is the black species initially formed from this reaction? Pohl (1953) postulated that the formation of $\mathrm{FeS}$ might be via the activated complex with a formula of $(\mathrm{FeSH})^{+}$. Baas Becking (1956) suggested that $\mathrm{Fe}(\mathrm{SH})_{2}$ was the first precipitated ferrous sulfide. Subsequently, Taylor (1980) suggested the formation of $\mathrm{FeSH}^{+}$as an intermediate, based on stereochemical arguments. Rickard $(1989,1991)$ studied this process experimentally and reported that the well known initial black precipitate is a neutral iron bisulfide ( $\left.\mathrm{Fe}(\mathrm{HS})_{2}\right)$ intermediate but not FeS. Luther (1991), by means of a polarographic technique, found that the sulfide product initially formed consists of (1) a complex of the form $\mathrm{Fe}(\mathrm{SH})^{+}$and (2) solid $\mathrm{FeS}$ for the reaction between $\mathrm{Fe}$ (II) and polysufides.

Apparently, the processes associated with the formation of $\mathrm{FeS}$ are still not well understood. Most recently Osseo-Asare and Wei (1992b) reported that the black intermediate formed initially is FeHS ${ }^{+}$intermediate, based on a kinetic study using a stopped-flow spectrophotometer. It was proposed that the pathway of $\mathrm{FeS}$ formation follows the sequence of $\mathrm{Fe}^{2+}+$ $\mathrm{HS}^{-}-->\mathrm{FeHS}^{+}-\rightarrow \mathrm{FeS}+\mathrm{H}^{+}$. To further confirm this mechanism, the thermodynamic study of this process, aimed at establishing the intermediate stoichiometry was done and the thermodynamic parameters were obtained for this reaction. 


\section{EXPERIMENTAL}

Reagent grade ferrous chloride $\left(\mathrm{FeCl}_{2}\right)$ and sodium sulfide $\left(\mathrm{Na}_{2} \mathrm{~S}\right)$ were obtained from Aldrich. Fe(II) stock solution with a concentration of $0.1 \mathrm{~mol} / 1$ was made by dissolving $\mathrm{FeCl}_{2}$ in oxygen-free distilled water containing $0.1 \mathrm{~N} \mathrm{HCl}$ to prevent $\mathrm{Fe}(\mathrm{OH})_{2}$ precipitation. Sulfide stock solution with a concentration of $0.1 \mathrm{~mol} / \mathrm{l}$ was made with $\mathrm{Na} 2 \mathrm{~S}$ and oxygenfree distilled water. These solutions were diluted further to obtain the required concentrations. The oxygen-free distilled water was prepared by bubbling purified $\mathrm{N}_{2}$ in distilled water for at least 5 hours. Both $\mathrm{Fe}(\mathrm{II})$ and sulfide stock solutions were prepared daily. The $\mathrm{pH}$ of the reaction between the two solutions was controlled by adjusting the $\mathrm{pH}$ of either the $\mathrm{Fe}$ (II) or sulfide solution via small additions of concentrated $\mathrm{HCl}$ or $\mathrm{NaOH}$. In the case of $\mathrm{pH}>7, \mathrm{NaOH}$ was added to the sulfide solution, while for $\mathrm{pH}<7$, $\mathrm{HCl}$ was added to the $\mathrm{Fe}(\mathrm{II})$ solution. The $\mathrm{pH}$ of the reaction mixture was measured immediately with a Model $701 \mathrm{~A}$ digital $\mathrm{pH} / \mathrm{mV}$ meter (Orion Research ) after the two solutions were mixed. The absorbance was measured by using a DX. 17 MV Sequential Stopped-Flow Spectrofluorimeter (Applied Photophysics) with an optical pathlength of 1 $\mathrm{cm}$. The temperature of the experiments was controlled at $25 \pm 0.5^{\circ} \mathrm{C}$.

In the experiments for determining the stoichiometry of the intermediate, the total concentration of $\mathrm{HS}^{-}$plus $\mathrm{Fe}^{2+}$ was maintained constant, while the mole ratio of $\mathrm{HS}^{-}$to $\mathrm{Fe}^{2+}$ was changed between 0.1 and 10. The absorbance was measured as a function of the variation of the mole ratio.

In the experiments for determining the equilibrium constant, the concentration of $\mathrm{Fe}^{2+}$ was fixed at $2.5 \times 10^{-4} \mathrm{M}$ at $\mathrm{pH} 7.4$, while the absorbance measurements were made for changing concentration of HS-. 


\section{RESULTS AND DISCUSSION}

\section{Determination of Stoichiometry}

The absorbance of the black species has a linear relationship with the concentration of $\mathrm{Fe}^{2+}$ when the mole ratio of $\mathrm{Na}_{2} \mathrm{~S}$ to $\mathrm{FeCl}_{2}$ is kept at 10 as shown in Figure 1. The absorptivity of the intermediate such determined is $4800(\mathrm{~mol} / \mathrm{l})^{-1} \mathrm{~cm}^{-1}$ (Osseo-Asare and Wei, 1992a). Based on this fact, the stoichiometry of the intermediate can be determined experimentally by fixing the total concentration of $\mathrm{HS}^{-}$plus $\mathrm{Fe}^{2+}$ and changing the mole ratio of $\mathrm{HS}^{-}$to $\mathrm{Fe}^{2+}$.

Consider the reaction:

$$
\begin{aligned}
& \mathrm{Fe}^{2+}+\mathrm{nHS}^{-}-->\mathrm{Fe}(\mathrm{HS})^{2-\mathrm{n}_{\mathrm{n}}}
\end{aligned}
$$

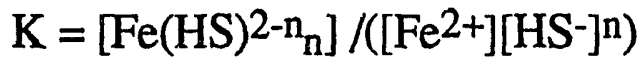

We can write:

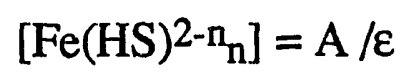

where $\mathrm{A}$ is the absorbance and $\varepsilon$ the absorptivity. Supposed the total concentration of $\mathrm{HS}^{-}$plus $\mathrm{Fe}^{2+}$ is $\mathrm{C}$ and the ratio of $\mathrm{HS}^{-}$to $\mathrm{Fe}^{2+}$ is $\mathrm{R}$, one has:

$$
\mathrm{C}=\left[\mathrm{Fe}^{2+}\right]+\left[\mathrm{HS}^{-}\right]
$$

and

$$
\mathrm{R}=\left[\mathrm{HS}^{-}\right] /\left[\mathrm{Fe}^{2+}\right]
$$


Substitution of Equations 3, 4 and 5 into 2 gives:

$$
A=\varepsilon K C^{n+1} R^{n} /(1+R)^{n+1}
$$

It can be proved that the maximum of $A$ will occur at $n=R$.

The variation in the absorbance as a function of $\mathrm{R}$ for two different total reactant concentrations is shown in Figure 2. It can be seen that the maximum absorbance occurs around $R=1$. This means that the stoichiometry of $\mathrm{n}$ should be 1 and consequently, Equation 1 can be rewritten as:

$$
\mathrm{Fe}^{2+}+\mathrm{HS}^{-}-.>\mathrm{Fe}(\mathrm{HS})^{+}
$$

This result is consistent with the findings made previously in our laboratory on the basis of kinetic investigations (Osseo-Asare and Wei, 1992b).

\section{Determination of Equilibrium Constant}

For the reaction shown in Equation 1, the equilibrium constant, $\mathrm{K}$, can be expressed as shown in Equation 2. Based on Beer's law, the absorbance can be writen as:

$$
\begin{aligned}
\mathrm{A} & =\varepsilon\left[\mathrm{Fe}(\mathrm{HS})_{\mathrm{n}}{ }^{2-\mathrm{n}}\right] \\
& =\varepsilon\left(\left[\mathrm{Fe}^{2+}\right]_{0}-\left[\mathrm{Fe}^{2+}\right]\right)
\end{aligned}
$$

and

$$
\begin{aligned}
A_{\infty} & =\varepsilon\left[\mathrm{Fe}(\mathrm{HS})_{\left.\mathrm{n}^{2-\mathrm{n}}\right]_{\infty}}\right. \\
& =\varepsilon\left[\mathrm{Fe}^{2+}\right]_{0}
\end{aligned}
$$


where $\varepsilon$ is the absorptivity $\left(4800(\mathrm{~mol} / \mathrm{l})^{-1} \mathrm{~cm}^{-1}\right)($ Osseo-Asare and Wei, 1992a), $\left[\mathrm{Fe}^{2+}\right]_{0}$ is the initial concentration of $\mathrm{Fe}^{2+}$, and $\mathrm{A}_{\infty}$ is the absorbance when all of $\mathrm{Fe}^{2+}$ converts to $\mathrm{Fe}(\mathrm{HS})_{\mathrm{n}}{ }^{2-\mathrm{n}}$. Hence,

$$
\begin{aligned}
\left(\mathrm{A}-\mathrm{A}_{\infty}\right) / \mathrm{A} & =-\left[\mathrm{Fe}^{2+}\right] /\left[\mathrm{Fe}(\mathrm{HS})_{\left.\mathrm{n}^{2-\mathrm{n}}\right]}\right. \\
& =-\mathrm{K}^{-1} /\left[\mathrm{HS}^{-}\right]^{\mathrm{n}}
\end{aligned}
$$

or

$$
\mathrm{A}=\mathrm{A}_{\infty}-\mathrm{K}^{-1} \mathrm{~A} /\left[\mathrm{HS}^{-}\right]^{\mathrm{n}}
$$

Noting that

$$
\begin{aligned}
{\left[\mathrm{HS}^{-}\right] } & =\left[\mathrm{HS}^{-}\right]_{0}-\mathrm{n}\left[\mathrm { Fe } \left(\mathrm{HS}_{\left.\mathrm{n}^{2-\mathrm{n}}\right]}\right.\right. \\
& =\left[\mathrm{HS}^{-}\right]_{0}-\mathrm{n} \mathrm{A} / \varepsilon
\end{aligned}
$$

Equation 11 becomes

$$
\mathrm{A}=\mathrm{A}_{\infty}-\mathrm{K}^{-1} \mathrm{~A} /\left(\left[\mathrm{HS}^{-}\right]_{0}-\mathrm{n} \mathrm{A} / \varepsilon\right)^{\mathrm{n}}
$$

When $n=1$, a plot of $A$ vs $A /\left(\left[\mathrm{HS}^{-}\right]_{0}-\mathrm{A} / \varepsilon\right)$ should be a straight line with a slope of $-\mathrm{K}^{-1}$ and an intercept of $\mathrm{A}_{\infty}$.

As shown in Figure 3, the straight line indicates that the value of $\mathrm{n}$ is equal to 1 . The slope of $-4.85 \times 10^{-5}$ gives the equilibrium constant $\mathrm{K}=$ 104.34. Because the forward rate constant, $\mathrm{k}_{1}$, is $10^{3.81} \mathrm{~s}^{-1}$, the reverse rate constant, $\mathrm{k}_{-1}$, can be calculated as $\mathrm{k}_{1} / \mathrm{K}$, which gives $\mathrm{k}_{-1}=10^{-0.53} \mathrm{~s}^{-1}$.

\section{CONCLUSIONS}

The results presented above show that the black material initially formed from the reaction between $\mathrm{Fe}^{2+}$ and $\mathrm{HS}^{-}$in solution is FeHS+ 
intermediate. The stoichiometry of the intermediate was determined by several methods and consistent results were obtained. The thermodynamic and kinetic parameters for the reaction of forming the intermediate were determined by means of spectrophotometric techniques. The equilibrium constant is $\mathrm{K}=10^{4.34}$; the forward rate constant $\mathrm{k}_{1}=103.81 \mathrm{~s}^{-1}$ and the reverse rate constant $k_{-1}=10^{-0.53} \mathrm{~s}^{-1}$.

\section{REFERENCES}

Baas Becking, L. G. M., 1956. Biological processes in the estuarine environment. VI. State of iron in the estuarine environment and iron sulfides. K. Ned. Akad. Wet. Proc. Ser. B., 59:181-189.

Berner, R. A., 1962. Tetragonal iron sulfide. Science. 137:669.

Berner, R. A., 1964. Iron sulfides formed from aqueous solution at low temperatures and atmospheric pressure. J. Geol., 72:293-306.

Berner, R. A., 1967. Thermodynamic stability of sedimentary iron sulfides. Amer. J. Sci., 265:773-785.

Berner, R. A., 1969. The synthesis of framboidal pyrites. Econ. Geol., 64:383-384.

Luther, G. W. III., 1991. Pyrite synthesis via polysulfide compounds.

Geochim. Cosmochim. Acta., 55:2839-2849.

Morse, J. W., Millero, F. J., Cornwell, J. C. and Rickard, D., 1987. The chemistry of the hydrogen sulfide and iron sulfide systems in natural waters. Earth Sci. Rev., 24:1-42.

Osseo-Asare, K and Wei, D., 1992a(August). Semiconductor electrochemistry of coal pyrite, Technical Progress Report for the peorid from April to June, 1992.

Osseo-Asare, K and Wei, D., 1992b(November). Semiconductor electrochemistry of coal pyrite, Technical Progress Report for the peorid from July to September, 1992.

Pohl, H. A., 1953. The formation and disso'ution of metal sulfides. J. Amer. Chem. Soc., 76:2182-2184. 
Rickard, D., 1969. The chemistry of iron sulphide formation at low temperatures. Stockholm Contrib. Geol., 20:67-95.

Rickard, D., 1975. Kinetics and mechanism of pyrite formation at low temperatures. Amer. J. Sci., 275:636-652.

Rickard, D., 1989. Experimental concentration-time curves for the iron(II) sulphide precipitation process in aqueous solutions and their interpretation. Chemical Geology. 78:315-324.

Rickard, D., 1991. Black amorphous iron sulphide is Fe(HS)2. First International Iron Sulphide Workshop. Cardiff, Wales, Ergland, Dec. 14, 1991.

Schoonen, M. A. A. and Barnes, H. L., 1991a. Reactions forming pyrite and marcasite from solution: I. Nucleation of $\mathrm{FeS}_{2}$ below $100^{\circ} \mathrm{C}$. Geochim. Cosmochim. Acta., 55:1495-1504.

Schoonen, M. A. A. and Barnes, H. L., 1991b. Reactions forming pyrite and marcasite from solution: II. Via FeS precursors below $100^{\circ} \mathrm{C}$. Geochim. Cosmochim. Acta., 55:1504-1514.

Schoonen, M. A. A. and Barnes, H. L., 1991c. Reactions forming pyrite and marcasite from solution: III. hydrothermal processes. Geochim. Cosmochim. Acta., 55:3491-3504.

Sweeney, R. E. and Kaplan, I. R., 1973. Pyrite framboid formation: Laboratory synthesis and marine sediments. Econ. Geol., 68:618634.

Taylor, P., 1980. The stereochemistry of iron sulfides: a structural rationale for the crystallization of some metastable phases from aqueous solution. Amer. Mineral.s 65:1025-1029. 


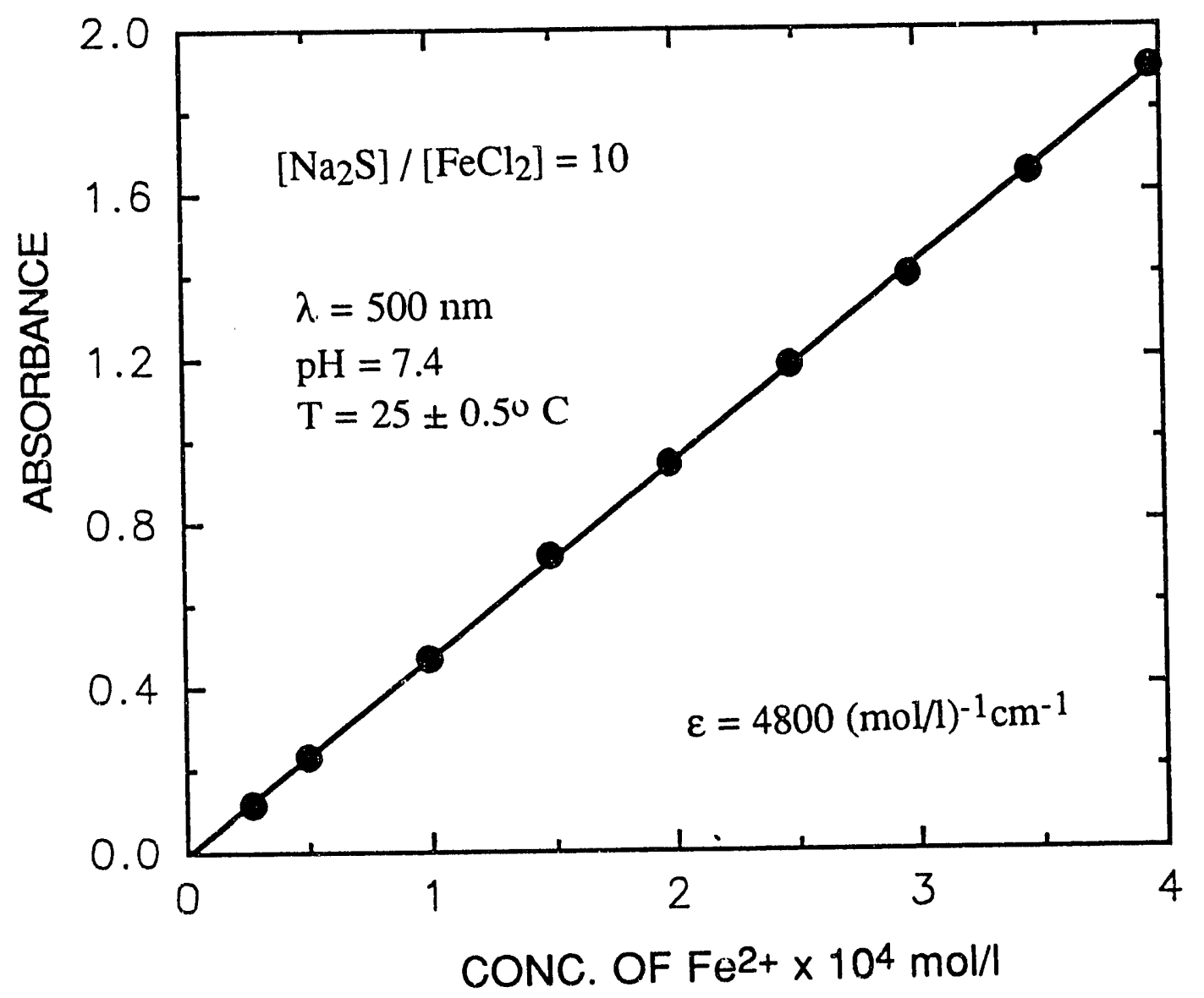

FIGURE 1. Absorbance vs concentration of $\mathrm{Fe}^{2+}$. 


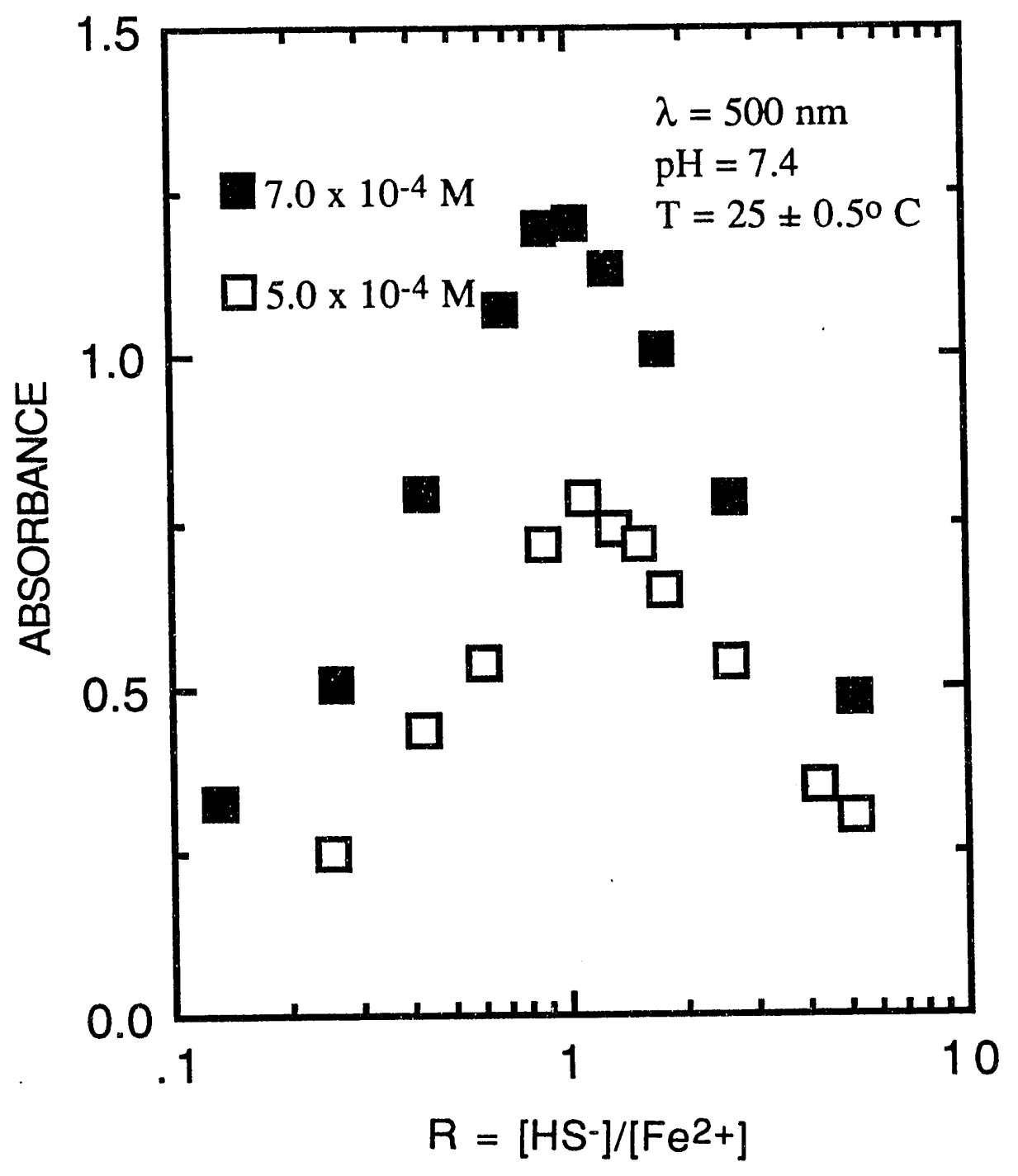

FIGURE 2. Stoichiometry determination for the reaction of Equation 1. 


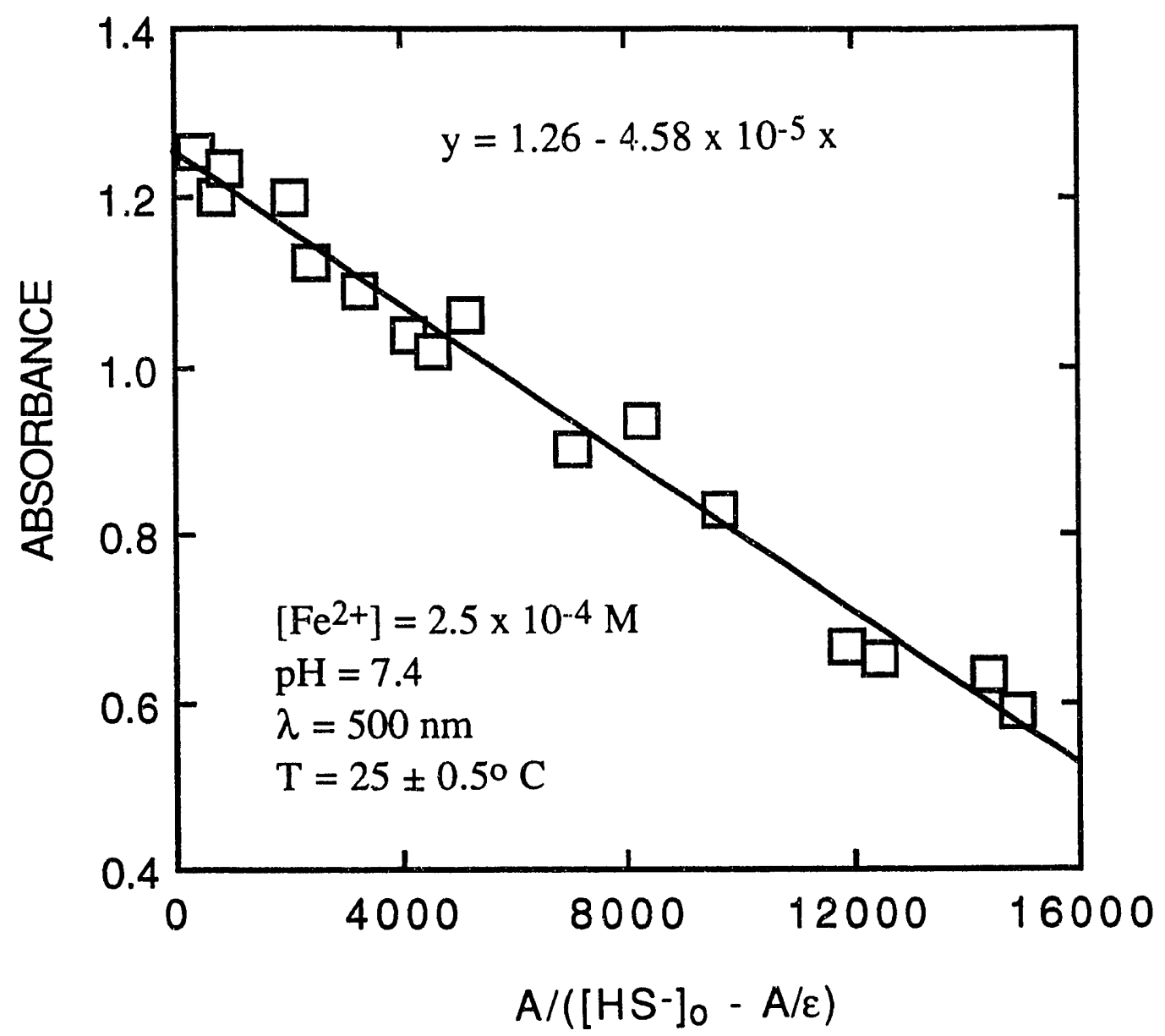

FIGURE 3. Equilibrium constant determination for the reaction of Equation 7. 

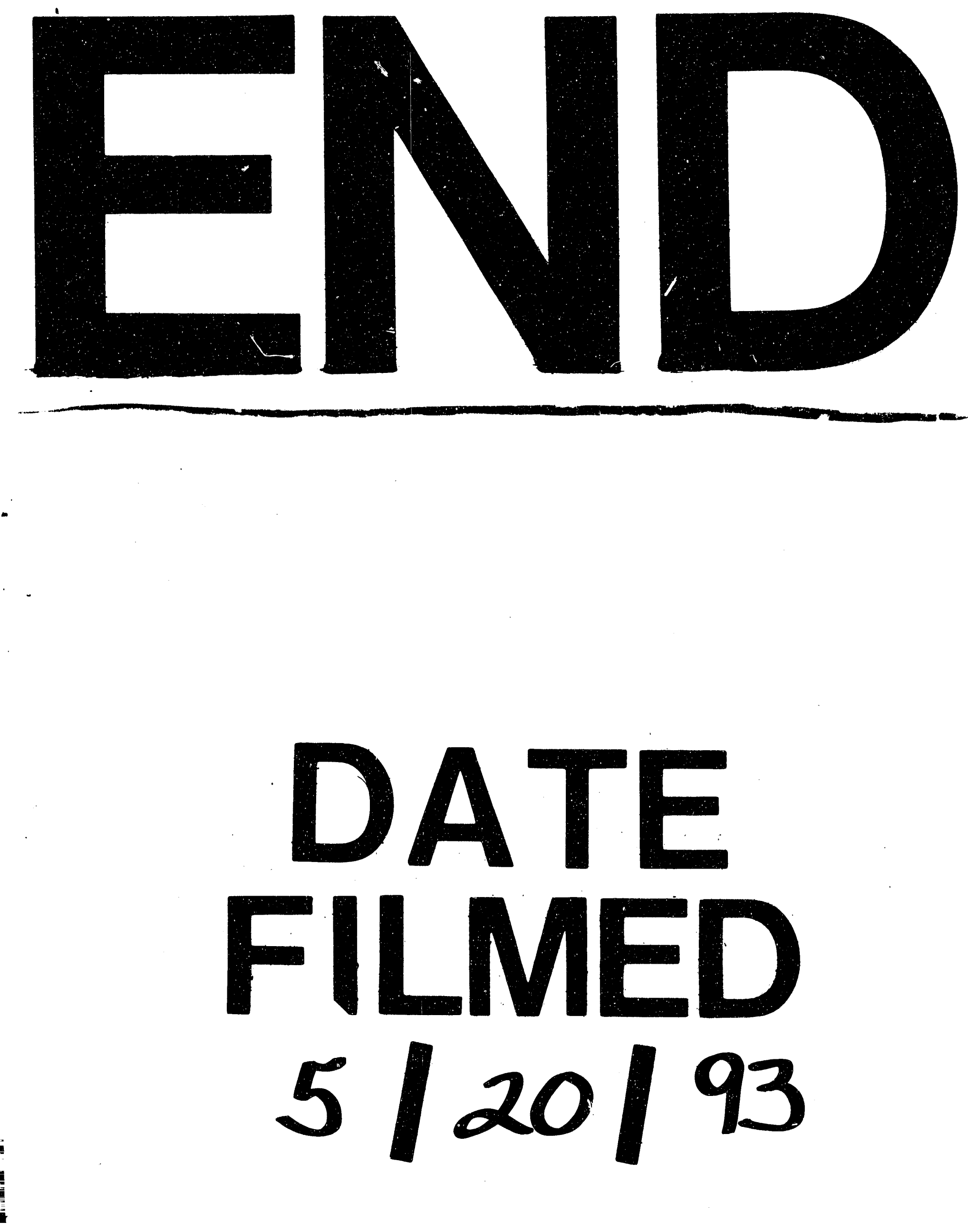
